\title{
The Application of Radon Measurement In the Active Fault Detection of Xiadian Fault
}

\author{
Lu Lina ${ }^{1,2^{*}}$, Li Jing ${ }^{1,2}$, and Yang Ming ${ }^{1,2}$ \\ ${ }^{1}$ Institue of Disaster Prevention, 065201 Sanhe, China \\ ${ }^{2}$ Hebei Key Laboratory of Earthquake Dynamics, 065201 Sanhe, China
}

\begin{abstract}
The Xiadian active fault is one of the most important seismological faults in the vicinity of Beijing-Tianjin-Hebei region. This paper mainly focuses on the geochemical characteristics of the fault to unveil and evaluate its activity. Via the application of soil gaseous radon measurement, a detailed field study at Qixinzhuang segment of Xiadian fault is proposed. Based on all the radon impulse value we acquired of 3 profiles in the study area. We plotted the radon impulse trend chart of 3 profiles, analyzed anomaly distribution of soil gaseous radon and discussed the scale and activity of the Xiadian fault. The radon multiple-peaks anomaly of Qixinzhaung segemnt demonstrates the hidden faults underground exist.
\end{abstract}

\section{Introduction}

The Xiadain fault is an important hidden active fault of Beijing plain area [1-2], located in the north of the North China Plate, general trend is NE45 ${ }^{\circ}$, extends $45 \mathrm{~km}$. Its formation and evolution play an important role in the tectonic evolution of Beijing plain areas. Among all the active fault exploration methods, measuring fault gas has the merits of easy, shortcut, economical and effective. Active fault as the natural channel of connecting the Earth's deep interior and deep gas release, fault-gas permeates in the vicinity of fault zone. A large number of data shows that the more active the fault is, the more fault-gas it has [3-6]. Based on this idea, In this paper, we used the method of soil gaseous radon measurement in Qixinzhuang section and carried on a detailed field survey on site. According to the radon impulse trend charts, we analyzed the characteristics of soil gaseous radon anomaly distribution and the spacial location of the fault in Qixinzhuang section and also discussed the scale and activity of Xiadian fault.

\section{Geological setting}

The Xiadain active fault, which is located in the northern North China Plate (Fig. 1), is one regional deep fault belt with a NNE trend of the lithosphere scale and located at the east gate of Beijing. Its formation and evolution plays an important role on Beijing plain region tectonic evolution. The fault zone is located north from Yuegezhuang area of Pinggu District, southwest by Ma Fang and Pangezhuang area, and south to the Yongle village. The whole fault is Northeast fortyfive degree and fortyfive kilometeres long. The biggest Cenozoic fault distance can be up to 3 or 4 kilometers during Cenozoic geological time. It is a basin boundary fault that controls the formation and evolution of the Dachang depression and constitutes the boundary between the Dachang depression and the Daxing uplift [7-8]. The 1679 Sanhe Earthquake caused the surface rupture of the Xiadian active fault zone, and the new Xiadian fault was formed on the fault zone. For the sake of discussion, the new Xiadian fault (NE trending) and the old Xiadian fault (NNE trending) are collectively referred to as the Xiadian active fault in this paper. In 1679, Sanhe earthquake formed a fault scarp of about 10 kilometers long on the earth's surface. The scarp is located west from Liuhetun area, through Pangezhuang and Qixinzhuang, and east to Dongxingzhuang area. This fault displays normal fault nature. The main lithology strata in the study area are shown in table 1. During the field work, the typical fault plane and significant fault scarp can be observed on the Qixinzhuang artificial exploratory trench profiles can be observed. According to the field measurement, the Qixinzhuang pofile of the fault has a strike of 45, a dip of 135 and a dip angle of 74 . Both sides of the fault are Quaternary accumulation. The horizontal bedding is developed at the bottom of the upper wall of the fault, and there is a traction in the thin clay silt layer.

\section{Methods and Results}

\subsection{Measuring line layout}

After the field survey, we can observe the typical fault plane and abvious fault escarpment in Qixinzhuang artificial exploratory trench profile. So we chose Qixinzhuang section (N39 $58^{\prime} 54.32^{\prime \prime}$, E116 $\left.55^{\prime} 54.32^{\prime \prime}\right)$ as the study area of the gaseous radon measurement. We set 3 isometric measuring profiles perpendicular to the

\footnotetext{
* Corresponding author: lulina@cidp.edu.cn
} 
fault strike. They are QX-1, QX-2 and QX-3 (Fig.1) and include 181 measuring points. And QX-2 profile lies in the south of QX-1 profile, instead, QX-2 profile is located in the north of QX-1 profile. The adjacent two measurement point interval is generally $10 \mathrm{~m}$ in every measuring line which extends $300 \mathrm{~m}$ at each side of the fault. The adjacent two parallel measuring line interval is $20 \mathrm{~m}$.

\subsection{Instrument introduction}

The most appropriate way to measure soil gaseous radon measuring method is conventional instantaneous method. The FD3017RaA gaseous radon measuring machine satisfies the requirement. It's very easy to operate and portable to carry. In addition, it has a high accuracy.

Table 1. Study area stratigraphic classification [9-10]

\begin{tabular}{cccc}
\hline System & Series & Formation & Codename \\
\hline \multirow{2}{*}{ Q } & Qh & Tianjin & QhT \\
& & Ouzhuang & QpO \\
& Qp & Yangliuqing & QpY \\
& & Gu'an & QpG \\
N & N2 & Minghuazhen & $\mathrm{N}_{2} \mathrm{M}$ \\
& $\mathrm{N} 1$ & Guantao & $\mathrm{N}_{1} \mathrm{G}$ \\
& & Dongying & $\mathrm{E}_{3} \mathrm{D}$ \\
& $\mathrm{E} 3$ & Shahejie & $\mathrm{E}_{3} \mathrm{~S}$ \\
& $\mathrm{E} 2$ & Kongdian & $\mathrm{E}_{2} \mathrm{~K}$ \\
\hline
\end{tabular}

Operating principle: The first generation of radon decay-RaA is electropositive. A negative pressure resulting from the high voltage electric field will absorb $\mathrm{RaA}$ on the metal wafer. RaA concentration on matal wafer is positively correlated with soil radon concentration. We can acquire the concentration of soil gaseous radon by calculation. The apparatus' limit of detection sensitivity is less than 0.1 Eman.

The operating condition for gas extraction is $60 \mathrm{~cm} \sim 80 \mathrm{~cm}$, depending on subsoil depth. The surveyor should take $1.5 \mathrm{~L}$ gas within $2 \mathrm{~min}$.

Before taking radon values using this instrument, we should choose the detection profiles first. Usually, three profiles are appropriate and caculated for one section of a fault. A profile should crosscut one fault, and 90 degree is the best crosscut angle. The surveying site between another surveying site is 10 meters as usual, and the perpendicular diatance between two profiles is 20 meters. Therefore obtaining these statistics data using this instument legitimately is the precondition for this fault activity study. Additionally, when you use this apparatus, you should don't use your tellphone or keep it far away; when the sampling apparatus is inserted into the soil, the surface of the soil should be sealed for the gas gathering; during the radon testing, the metal sheet can be touched with the sheetmetal margin, and the surface can't be touched, otherwise you will obtain invalid radon value of this testing.

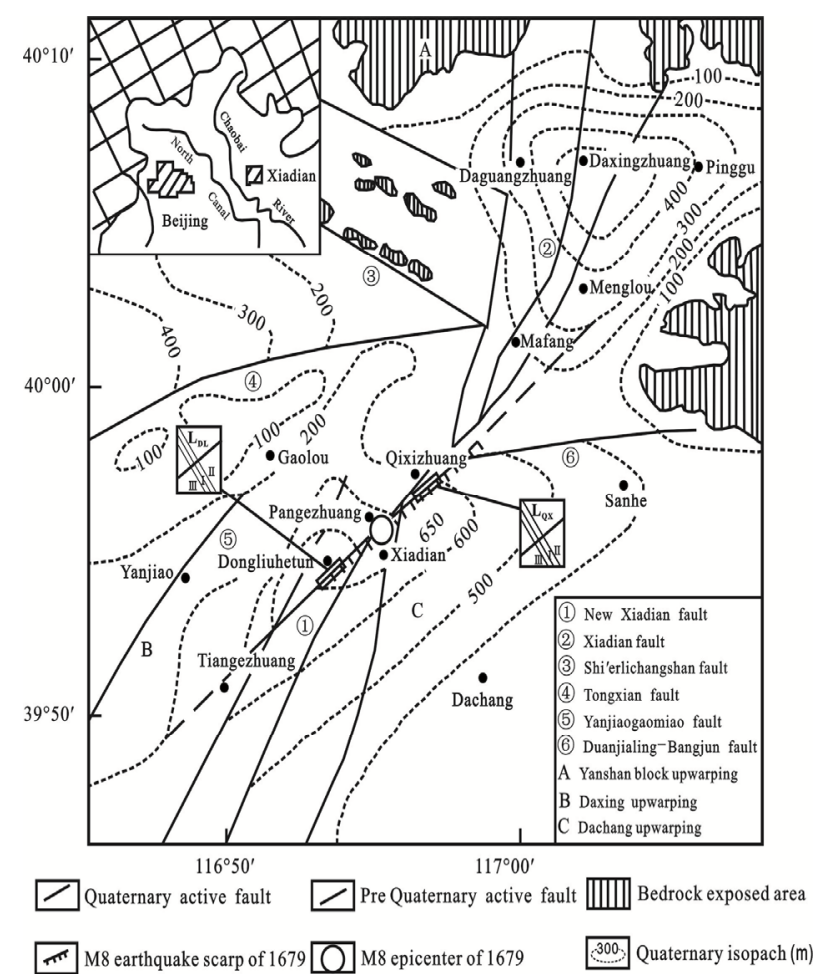

Fig. 1. The working area map of Xiadian Active Fault [11]

\subsection{Analysis of the result}

This study attained all 181 soil radon geochemical sample data in Xiadian fault, which is the measurement result of the 3 profiles. Each profile owns 60 sample data approximately. In accordance with measurement result, we ploted the impulse graph of each profile (Fig. 2, 3, 4).

We can see from the anomalous curve (Fig. 2, 3, 4) in Qixinzhuang section that the profile QX-1, QX-2 and QX-3 all have conspicuous peak value in each radon impulse graph which is the direct reflection of radon concentration anomaly in each profile. The higher the peak value is, the radon anomaly is more evident. The figures 2, 3 and 4 show that, every one of profile has a higher radon impulse anomaly at the first half part.

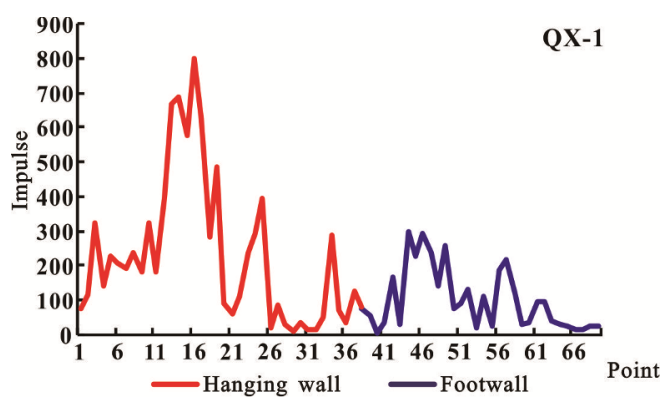

Fig. 2. QX-1 radon impulse graph 


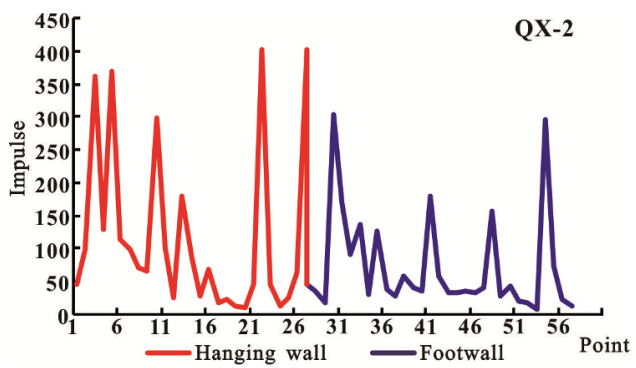

Fig. 3. QX-2 radon impulse graph

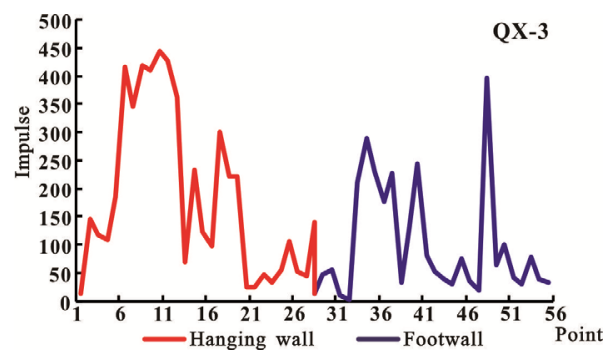

Fig. 4. QX-3 radon impulse graph

\section{Discussions}

\subsection{Fault spacial location analysis}

Our work is based on predecessors' work [12] and proceed to carry on exploratory trench excavation. We detected the multiple peaks anomaly of Rn impulse in 3 profiles (QX-1, QX-2 and QX-3) at Qixinzhaung section. And then it unveiled the multiple peaks anomaly of Rn concentration. Multiple peaks anomaly suggests that there are more faults lying underground. Multitudes of abnormal secondary peaks (Fig. 2, 3, 4) imply the location of the branch hidden faults of the major fault. Among the 3 parallel profiles, the abonomal secondary peaks of each profile exists in different dot mark, which demonstrates that the relavent hidden fault exists in different location. On account of that the hanging wall is more active than the footwall and has more fissure than the footwall. Combined with $\mathrm{Rn}$ geochemical characteristics, we can acquire that No.1 to 37 stands for the hanging wall of QX-1 profile. In the same way, the hangng wall of QX-2 and QX-2 are No.1 to 26 and No.1 to 27 . And the rest of the dot marks of each profile represents the footwall. The analysis fits the practical observation. The peak anomaly in the hanging wall is much higher than the footwall. According to the exploratory trench location and fault strike, we infer that No.6 to 51 of Qixinzhuang profile is the location of the main fault.

\subsection{Fault scale and activity analysis}

The accurate location and activity natures of this blind active fault zone are detected by kinds of comprehensive detection and trench digging. Therefore, uncertainties can be excluded in the progress of the soil gas radon characteristics for the Xiadian buried fault zone, and data interpretation is also excluded. Practice indicates that the more big dimension of the fault is, the more radon anomaly plots are and the higher anomaly peak is. On the contrary, the more small dimension of the fault is, the even less radon anomaly plots are and the lowerer anomaly peak is, and usually the single and double peak [13]. According to the radon geochemistry characteristics of the Xiadian fault and the collected data [14], the Qixinzhuang section is larger than the Liuhetun section on the scale for the blind fault under the earthground.

The practice shows that for the large scale fault, the more radon anomalous values are, then the higher points of the peak value is. On the contrary, the smaller fault scale has less anomalous points, and the peak is lower usually with mono-peaks or double-peaks [15] anomaly. Multiple peaks anomaly generally exists in deep fault zone. The fault zone may have multiple branch hidden faults [16]. According to the main fault location and the multiple peaks anomaly of radon impulse, it indicates that Qixinzhuang section of Xiadian fault's activity is intense. Reaserch show that fault activity nature is closed bound up with radon gas concentration. If the regional geological setting is generally consisitent, the high radon concetration, the large gradient and many anomalies show powerful fault active nature, conversely the low radon concetration, the small gradient and lack of anomalies show weak activity [17]. The radon impulse values are higher on the Xiadian profile than that on the Liuhetun of the Xiadian buried fault. The radon contration ratio conditon is just like that of the radon impulse value. The anomalies plots of the Qixinzhuang profile are more than that of the Liuhetun of the Xiadian hidden active fault. Also, the Qixinzhuang profile has more remarkable radon change of gradient than the Liuhetun profile. These data and phenomena abundantly indicate that the Qixinzhuang profile is more active than the Liuhetun of the Xiadian blind fault zone.

\section{Summary}

The soil gaseous radon impulse-value distribution plots (Fig.2, 3, 4) of Xiadain fault clearly reflect the location and activity of the fault. The soil gaseous radon impulse anomaly of Xiadian fault indicates that the multiple peaks anomaly of Radon impulse value at Qixinzhaung section where multiple hidden faults exist. The dot mark No.1 to 37, No.1 to 26 and No.1 to 27 of each profile respectively reprensents the hanging wall of QX-1,QX-2 and QX-3 profile. The dot mark No.6 to 51 is the range of soil gaseous radon which implys the location of the main fault.

This research and collected data show that there is a blind active fault which is named the Xiadian fault zone from the soil gas randon impulse graphs. The fact that the soil gas radon concentration show many anomalies with lots of peaks indicates that the Xiadian fault zone is composed of some blind faults under the Qixinzhuang and Liuhetun profile. According to radon concentration isoline graph, the whole strike at the Qixinzhuang and Liuhetun of the Xiadian buried fault zone is forty-five degree. The characteristics of many anomalies and high peak value infer that the active intensity of the 
Qixinzhuang profile is more strong than the Liuhetun profile of the Xiadian hidden fault zone. Therefore, the Qixinzhuang pofile of the Xiadian fault zone should be the key locality for seismological monitoring in future.

\section{Acknowledgements}

This reserach was jointly funded by the National Natural Science Foundation of China [No. 41802084] and the State Key Laboratory of Ore Deposit Geochemistry Foundation of Institute of Geochemistry, Chinese Academy of Sciences [No. 201705].

\section{References}

1. Jiang W.L, Hou Z.H., Xiao Z.M, Xie X.S.. (2000) Study on Paleoearthquakes of Qixinzhuang Trench at the Xiadian Fault, Bejing Plain. Seismology \& Geology, 22(4):413-422.

2. Han X.K, Li Y., Du J.G., Zhou X.C., Li X.Q.. (2013) Geochemical Characteristics of Soil Gas in the Central South Segment of Xiadian Fault. Geophysical \& Geochemical Exploration, 37(6):976-982.

3. Wei B.L, Huang H.S, Chen P.L., Li F.G., Xu H.L.. (1998) A Study on Fault Activity and Statutory by Geochemical Prospecting. South China Journal of Seismology, (4):50-58.

4. Jia G.X., Zhao Y.F., Yao J.Q., Yan Z.J., Li S.J.. (2005) Research and Applicaton of Radon Gas Geochemical Exploration:Interference Factors and Its Eliminating Method[J]. Mineral Resources \& Geology, 19(6):653-659.

5. Liu J.H., Wang Z.W., Liu S.T., Wang X.L.. (2006) The Evaluation Method of Soil Radon and Mercury Gas Measurement about Urban Active Fault Zones. Journal of Jilin University, 36(2):295-297.

6. Wang X.L., Liu J.H., Wang Z.W, Zhang Y.L.. (2007) Numerical Simulation of Radon Movement in Quatenary Overburden over the Fault. Geophysical \& Geochemical Exploration, 27(4):186-91.

7. He F.B., Bai L.Y., Wang J.M, Liu Y..(2013) Deep structure and quaternary activities of the Xiadian fault zone. Seismology and Geology, (03): 490-505.

8. Ran Z.J., Li H., Lv G.J., Wen C., Yang L., Yang Q.Y., Meng L.P., Peng Y.Q., Luo Y.X.. (2013) Seismic detecting for the shallow tectonic features of the XiaDian fault. China Earthquake Engineering Journal, (03): 656-663.

9. Ju Z.Y., Li Q., Zhang Y.H.. (1989) Regional Geology of Beijing, Tianjin and Hebei Province. Geology Press, Beijing.

10. Zhang L.L. (2012) Quaternary stratigraphic division and Contradistinction study of Langfang city. A master degree paper, 1-70.

11. Gao Z.W, Xu J., Song C.Q., Sun J.B.. (2001) The Segmental Character of Zhangjiakou-Penglai Fault. North China Earthguake Sciences, (01): 35-42+54.
12. Jiang W.L., Hou Z.H., Su Y.Z., Zhang Y.L., Xie X.S., Xiao Z.M.. (2000) Crustal tectonics and crustal press collection. Institute of Crustal Dynamics, China Earthquake Administration, Beijing: 1-15.

13. Li L., Zhang S.H., Cai X.M., Yang T.S., Wang J.M., Wu H.C.. (2011) Magnetic investigation on activity of the Xiadian fault in the Beijing plain. In: The 27th Symposium of Chinese Geophysical Society. Anhui. 161.

14. Lu L.N., Yang M., Li J., Li H.L., Duan M.F., Li B.J.. (2018) The application research of soil-gas mercury detection in the Xiadian fault zone. Geology and Exploration, 54(1): 112-120.

15. Li H.Y., Zheng C.B., Liang S.R., Zhang Y.D.. (2011) Application and Influencing Factors of Variational Curve of Soil Radon Concentration in Fracture Zone. Shanghai Land \& Resources, 32(1):78-83.

16. Lu L.N., Li J., Shen J., Sheng S.Z., Yang M., Li B.J., Gong L.W.. (2016) Geochemical Characteristics of Soil Radon in the Xiadian Active Fault. Tchnology for Earthquake Disaster Prevention, 11(4) : 736-746.

17. Liu J.H., Wang Z.W., Liu S.T., Wang X.L.. (2006) The evaluation method of soil radon and mercury gas measurement about urban active fault zones. Journal of Jilin University(Earth Science Edition), (02): 295-297. 